\title{
Pathogenic Lysosomal Depletion in Parkinson's Disease
}

\author{
Benjamin Dehay, ${ }^{1 *}$ Jordi Bové, ${ }^{*}$ Natalia Rodríguez-Muela, ${ }^{2}$ Celine Perier, ${ }^{1}$ Ariadna Recasens, ${ }^{1}$ Patricia Boya, ${ }^{2}$ \\ and Miquel Vila ${ }^{1,3}$ \\ ${ }^{1}$ Neurodegenerative Diseases Research Group, Vall d'Hebron Research Institute-Center for Networked Biomedical Research on Neurodegenerative Diseases (CIBERNED), \\ Barcelona 08035, Spain, 23D Laboratory (Development, Differentiation \& Degeneration), Cellular and Molecular Medicine, Biological Research Center-Spanish National \\ Research Council (CIB-CSIC), Madrid 28040, Spain, and ${ }^{3}$ Catalan Institution for Research and Advanced Studies (ICREA), 08035 Barcelona, Spain
}

Mounting evidence suggests a role for autophagy dysregulation in Parkinson's disease (PD). The bulk degradation of cytoplasmic proteins (including $\alpha$-synuclein) and organelles (such as mitochondria) is mediated by macroautophagy, which involves the sequestration of cytosolic components into autophagosomes (AP) and its delivery to lysosomes. Accumulation of AP occurs in postmortem brain samples from PD patients, which has been widely attributed to an induction of autophagy. However, the cause and pathogenic significance of these changes remain unknown. Here we found in the 1-methyl-4-phenyl-1,2,3,6-tetrahydropyridine mouse model of PD that AP accumulation and dopaminergic cell death are preceded by a marked decrease in the amount of lysosomes within dopaminergic neurons. Lysosomal depletion was secondary to the abnormal permeabilization of lysosomal membranes induced by increased mitochondrialderived reactive oxygen species. Lysosomal permeabilization resulted in a defective clearance and subsequent accumulation of undegraded AP and contributed directly to neurodegeneration by the ectopic release of lysosomal proteases into the cytosol. Lysosomal breakdown and AP accumulation also occurred in PD brain samples, where Lewy bodies were strongly immunoreactive for AP markers. Induction of lysosomal biogenesis by genetic or pharmacological activation of lysosomal transcription factor EB restored lysosomal levels, increased AP clearance and attenuated 1-methyl-4-phenylpyridinium-induced cell death. Similarly, the autophagy-enhancer compound rapamycin attenuated PD-related dopaminergic neurodegeneration, both in vitro and in vivo, by restoring lysosomal levels. Our results indicate that AP accumulation in PD results from defective lysosomal-mediated AP clearance secondary to lysosomal depletion. Restoration of lysosomal levels and function may thus represent a novel neuroprotective strategy in PD.

\section{Introduction}

Parkinson's disease (PD) is a common neurodegenerative disorder of unknown origin mainly characterized by the loss of dopaminergic neurons from the substantia nigra pars compacta $(\mathrm{SNpc})$ and the presence, in the affected brain regions, of ubiquitinated intraneuronal proteinacious cytoplasmic inclusions called Lewy bodies (Dauer and Przedborski, 2003). The presence of Lewy bodies in PD suggests that defective protein handling may contribute to the pathogenesis of the disease. Proteasomal and autophagic proteolysis are the two major pathways for degradation of cellular constituents in eukaryotic cells. While initial reports focused on the proteasomal system, mounting evidence indicates that alterations in autophagic pathways may be preferentially involved in neurodegenerative diseases, including PD (Levine and Kroemer, 2008). Autophagy refers to the

\footnotetext{
Received April 15, 2010; revised July 15, 2010; accepted July 17, 2010.

This work was supported by European Commission Marie Curie Excellence Grant and Marie Curie International Reintegration Grant (M.V.), Fundació la Caixa, Spain (M.V., P.B.), Fondo de Investigación Sanitaria-Instituto de Salud Carlos III,Spain (M.V.), Ministerio de Ciencia e Innovación (MICINN), Spain (P.B.), Comunidad de Madrid, Spain (P.B.), and Ramón y Cajal (C.P., P.B.) and Formación del Profesorado Universitario programmes (N.R.-M.) from MICINN, Spain. B.D. is the recipient of a fellowship award from the Foundation Bettencourt-Schueller (France). We thank Annabelle Parent and Esther Pérez for their technical assistance, and Eeva-Liisa Eskelinen, Marta Martínez-Vicente, Sophie Pattingre, and José Manuel Fuentes for their insightful comments.

*B.D. and J.B. contributed equally to this work.

Correspondence should be addressed to either of the following: Miquel Vila, Vall d'Hebron Research Institute, Pg. Vall d'Hebron 119-129, Barcelona 08035, Spain, E-mail: mvila@ir.vhebron.net; or Patricia Boya, Centro de Investigaciones Biológicas (CIB-CSIC), Ramiro de Maeztu 9, Madrid 28040, Spain, E-mail: pboya@cib.csic.es.

DOI:10.1523/JNEUROSCI.1920-10.2010

Copyright $\odot 2010$ the authors $\quad 0270-6474 / 10 / 3012535-10 \$ 15.00 / 0$
}

global process by which intracellular components are degraded by lysosomes, i.e., cytoplasmic membrane-enclosed organelles that contain a wide variety of hydrolytic enzymes and control the intracellular turnover of macromolecules (Luzio et al., 2007). While chaperone-mediated autophagy (CMA) involves the selective targeting of particular proteins directly to lysosomes, the bulk degradation of cytosolic proteins and organelles is largely mediated by macroautophagy. Macroautophagy involves the formation of double-membrane-bounded structures known as autophagosomes (AP) that fuse with lysosomes to form single-membrane-bound autophagolysosomes, which contents is then degraded by acidic lysosomal hydrolases.

While alterations in CMA have been linked to PD because of the ability of mutant and posttranslationally modified $\alpha$-synuclein to block CMA in vitro (Cuervo et al., 2004; Martinez-Vicente et al., 2008), macroautophagy dysregulation is increasingly recognized as a potential pathogenic factor in neurodegeneration. For instance, constitutive macroautophagy is essential for neuronal survival, as its genetic inactivation selectively in neurons leads to the formation of ubiquitinated intracellular inclusions and neuron cell loss in mutant mice (Hara et al., 2006; Komatsu et al., 2006). Relevant to $\mathrm{PD}$, macroautophagy is the primary mechanism by which longlived proteins, such $\alpha$-synuclein, are degraded and is the only mechanism by which entire organelles, such as mitochondria, are recycled (C. T. Chu et al., 2007; Mizushima, 2007; Vogiatzi et al., 2008). Both mitochondrial dysfunction and $\alpha$-synuclein accumulations play major pathogenic roles in PD (Dauer and Przedborski, 2003; 
Vila et al., 2008; Hattingen et al., 2009). Increased number of AP has been observed in cultured cells intoxicated with parkinsonian neurotoxins, such as 1-methyl-4-phenylpyridinium $\left(\mathrm{MPP}^{+}\right)$, rotenone, and 6-OHDA (Chen et al., 2007; Zhu et al., 2007; Dagda et al., 2008), and in postmortem PD brain samples (Anglade et al., 1997). While these changes have been widely interpreted as an induction of autophagy in these pathological situations, the actual cause and pathogenic significance of these observations remain unknown.

Here we show that AP accumulation in experimental PD is preceded by an early disruption of lysosomal integrity caused by the abnormal permeabilization of lysosomal membranes through mitochondrially driven oxidative attack. In addition to overloading the system with undegraded AP, lysosomal breakdown directly contributes to neuron cell death by the ectopic release of lysosomal proteases into the cytosol. Genetic or pharmacological restoration of lysosomal levels in experimental PD attenuates AP accumulation and dopaminergic cell death, and may thus represent a novel potential neuroprotective strategy in PD.

\section{Materials and Methods}

Cell culture and plasmids. Human neuroblastoma cell line BE-M17 (M17 EV) was provided by B. Wolozin (Boston University School of Medicine). Cells were grown in OPTIMEM (Cell Grow) plus 10\% fetal bovine

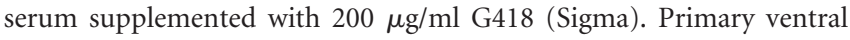
midbrain neurons were obtained from day $0-2$ postnatal rats, as previously described (Dauer et al., 2002). Transient transfections with cDNAs were performed with Lipofectamine 2000 (Invitrogen), following manufacturer recommendations, to label lysosomes with Lamp1-GFP construct (provided by Jeniffer Lippincott-Schwartz, National Institutes of Health, Bethesda, MD) and autophagosomes with GFP-LC3 or tfLC3 constructs (provided by T. Yoshimori, Osaka University, Japan). The Homo sapiens TFEB cDNA clone (MGC:40490, IMAGE:5180066) was obtained from ATCC. For drug treatments, cells were grown to $70-80 \%$ confluency and treated for 24 and $48 \mathrm{~h}$. Each experiment was reproduced at least in three independent series.

RNA extraction and reverse transcriptase PCR. Total cellular RNA was prepared using the RNeasy Protect Mini Kit (Qiagen) following the manufacturer's indications, and used for reverse transcriptase PCR analysis using the following primer sequences: LAMP1 human, $5^{\prime}$-CTGCCTTTAAAGCTGCCAAC-3' and 5'-TGTTCTCGTCCAGCAGACAC-3'; LAMP1 mouse, $5^{\prime}$-ATGGCCAGCTTCTCTGCCTCC and 5' -ACAGTGGGGTTTGTGGGCAC-3'; GAPDH human, 5'-AGAAGGCTGGGGCTCATTTG-3' and 5'-AGGGGCCATCCACAGTCTTC-3'; GAPDH mouse, 5'-ATGGCCAGCTTCTCTGCCTCC-3' ${ }^{\prime}$ and $5^{\prime}$-ACAGTGGGGTTTGTGGGCAC-3'; Tubulin mouse, 5'-GACAGAGGCAAACTGAGCACC-3', and 5'-CAAC GTCAAGACGGCCGTGTG 3'. Reactions products were separated electrophoretically on a $2 \%$ agarose gel and visualized by SYBR Safe DNA gel staining.

Cell viability assay and flow cytometry. Cell viability was estimated by MTT assay (ATCC/LGC Promochem) following manufacturer recommendations. Apoptotic cells were quantified by flow cytometry after propidium iodide (PI) staining. At selected time-points after treatment, cells were detached and collected by centrifugation, resuspended and fixed in $70 \%$ ethanol at $-20^{\circ} \mathrm{C} \mathrm{O} / \mathrm{N}$. After centrifugation, the pellet was stained for $30 \mathrm{~min}$ with $50 \mu \mathrm{g} / \mathrm{ml}$ PI staining solution ( $3.8 \mathrm{~mm}$ sodium citrate, 50 $\mu \mathrm{g} / \mathrm{ml}$ RNaseA in PBS). Fluorescence measurements and analyses were performed using FACSCalibur flow cytometer (BD).

Histochemistry, immunohistochemistry, and electron microscopy. Cells were fixed in $4 \%$ paraformaldehyde. To label lysosomes, cells were stained with either $0.5 \mu \mathrm{M}$ LysoTracker Red (Invitrogen) or $10 \mu \mathrm{g} / \mathrm{ml}$ acridine orange (AO) (Invitrogen) for $15 \mathrm{~min}$ at $37^{\circ} \mathrm{C}$ and then analyzed by fluorescence microscopy. For Cathepsin B and TFEB immunostaining, mouse monoclonal antibodies were purchased from Sigma and Millipore Bioscience Research Reagents, respectively (1:1000). Cell nuclei were visualized using Hoechst (Invitrogen) at $10 \mu \mathrm{M}$ for $10 \mathrm{~min}$. Fluorescence was analyzed using a Zeiss Axio Imager D1 fluorescence microscope or an Olympus FV1000 confocal microscopy. For EM, cells were detached after selected treatments, pelleted and fixed in $2 \%$ glutaraldehyde for $2 \mathrm{~h}$ at $4^{\circ} \mathrm{C}$, then postfixed in $1 \%$ osmium tetroxide for $1 \mathrm{~h}$ at $4^{\circ} \mathrm{C}$. The samples were dehydrated, embedded in plastic, and cut into in $70 \mathrm{~nm}$ sections for microscopy. Sections were subsequently poststained with $5 \%$ uranyl acetate. Samples were viewed with a JEOL JEM 1010 electron microscope.

Cell lysates and Western blot analysis. Cells were washed by cold PBS at $4^{\circ} \mathrm{C}$ and lysed in a buffer containing $25 \mathrm{~mm}$ Tris $\mathrm{HCl}$ pH6.8, $1 \%$ SDS, 250 mм DTT, Glycerol 7.5\% and $0.05 \%$ bromophenol blue. For immunoblotting, $40 \mu \mathrm{g}$ of protein were loaded per lane and separated on $15 \%$ SDS-PAGE, transferred to nitrocellulose membranes, and immunoblotted with rabbit anti-LC3 (1:1000; Novus Biologicals), rabbit anti-Lamp1 (1:1000; GeneTex), mouse anti-cathepsin D (1:1000; Sigma) or mouse anti-GFP (1:1000; Clontech). Mouse anti-actin antibody (1:5000; Sigma) was used as loading control.

Isolation of lysosomal fractions. Mouse brain lysosomes were isolated from a light mitochondrial-lysosomal fraction in an OptiPrep density gradient (Lysosome Isolation Kit, Sigma) according to the manufacturer instructions. In all the experiments, lysosomal integrity was verified after isolation by measuring the activity of acid phosphatase and $\beta$-hexosaminidase, two lysosomal enzymes, in the incubation medium. Preparations containing $>10 \%$ of broken lysosomes were immediately discarded. Cytosolic fractions were prepared by centrifugation of the supernatant of the light mitochondrial-lysosomal fraction at $100,000 \times g$ for $30 \mathrm{~min}$.

LysoTracker labeling and quantification. To label lysosomes, LysoTracker Red (Invitrogen) was used at a final concentration of $75 \mathrm{~nm}$. Cells intoxicated for $3 \mathrm{~h}$ with different doses of $\mathrm{MPP}^{+}$were loaded with LysoTracker Red for $30 \mathrm{~min}$ at $37^{\circ} \mathrm{C}$ before being collected. Cells were washed twice in PBS and immediately analyzed by flow cytometry. Decreases in fluorescence intensity corresponded to increases in lysosomal pH or LMP. A minimum of 15,000 cells were analyzed for each sample.

1-Methyl-4-phenyl-1,2,3,6-tetrahydropyridine-intoxicated mice. Eightto 10 -week-old male C57BL/6 mice received one intraperitoneal injection of 1-methyl-4-phenyl-1,2,3,6-tetrahydropyridine (MPTP)-HCl per day (30 mg/kg free base; Sigma) for five consecutive d. Control mice received saline injections only. Mice were killed at different time-points after MPTP intoxication: 0 (immediately after the last MPTP injection), $1,2,4,7$, and $21 \mathrm{~d}$ after the last MPTP administration. Six to seven mice were used in each group. Mice were decapitated and once the brain was removed, the ventral midbrain, which contains the $\mathrm{SNpc}$, was dissected and stored at $-80^{\circ} \mathrm{C}$. Total tissue proteins were isolated in $50 \mathrm{~mm}$ Tris$\mathrm{HCl}, \mathrm{pH}$ 7.0/150 mм NaCl/5 mм EDTA/1\% SDS/1\% Nonidet P-40/ protease inhibitors (Mini mixture; Roche Diagnostics). For Western blot analyses, proteins were separated by SDS-PAGE and transferred to nitrocellulose membranes. Incubation of the primary antibodies was performed overnight at $4^{\circ} \mathrm{C}$ with antibodies against Lamp1 (1:1000; GeneTex) and LC3 (1:1000; Novus Biologicals). Antibody against actin (1:5000; Sigma) was used as a loading control. For double immunofluorescence studies, mice were transcardially perfused with $4 \%$ paraformaldehyde, and the removed brains were immersed overnight in the same fixative solution, then cryoprotected with $30 \%$ sucrose for $2 \mathrm{~d}$ and finally frozen by immersion in 2-methylbutane at $-40^{\circ} \mathrm{C}$. Brains were cut at 30 $\mu \mathrm{m}$ through the entire substantia nigra with a cryostat. Double immunofluorescence was performed in free-floating sections with a monoclonal antibody against tyrosine hydroxylase (TH) (1:800; Millipore Bioscience Research Reagents) and Lamp1 (1:250; GeneTex). Nuclei were visualized using Hoechst (Invitrogen). Fluorescence was analyzed using an Olympus FV1000 confocal microscope. Regarding the experiments with rapamycin, MPTP-intoxicated mice were pretreated with rapamycin for $2 \mathrm{~d}$ (i.p., $10 \mathrm{mg} / \mathrm{kg} / \mathrm{d}$ ) and then treated with daily doses of rapamycin (i.p., $5 \mathrm{mg} / \mathrm{kg} / \mathrm{d}$ ) up to $4 \mathrm{~d}$ after the last MPTP injection. Rapamycin was administered in $4 \%$ ethanol, $5 \%$ Tween $80,5 \%$ Polyethylene glycol 400 (PEG 400) in saline. Vehicle- and rapamycin-treated mice were killed 2 weeks after the last MPTP injection and their brains were processed for morphology to assess: (1) the number of TH-positive SNpc dopaminergic neurons, by stereology, using the optical fractionator method (StereoInvestigator; MBF Bioscience, Williston, VT) and (2) the extent of striatal dopaminergic denervation, by optical densitometry.

Postmortem brain samples. Postmortem human brain samples were obtained from the New York Brain Bank at Columbia University, the 

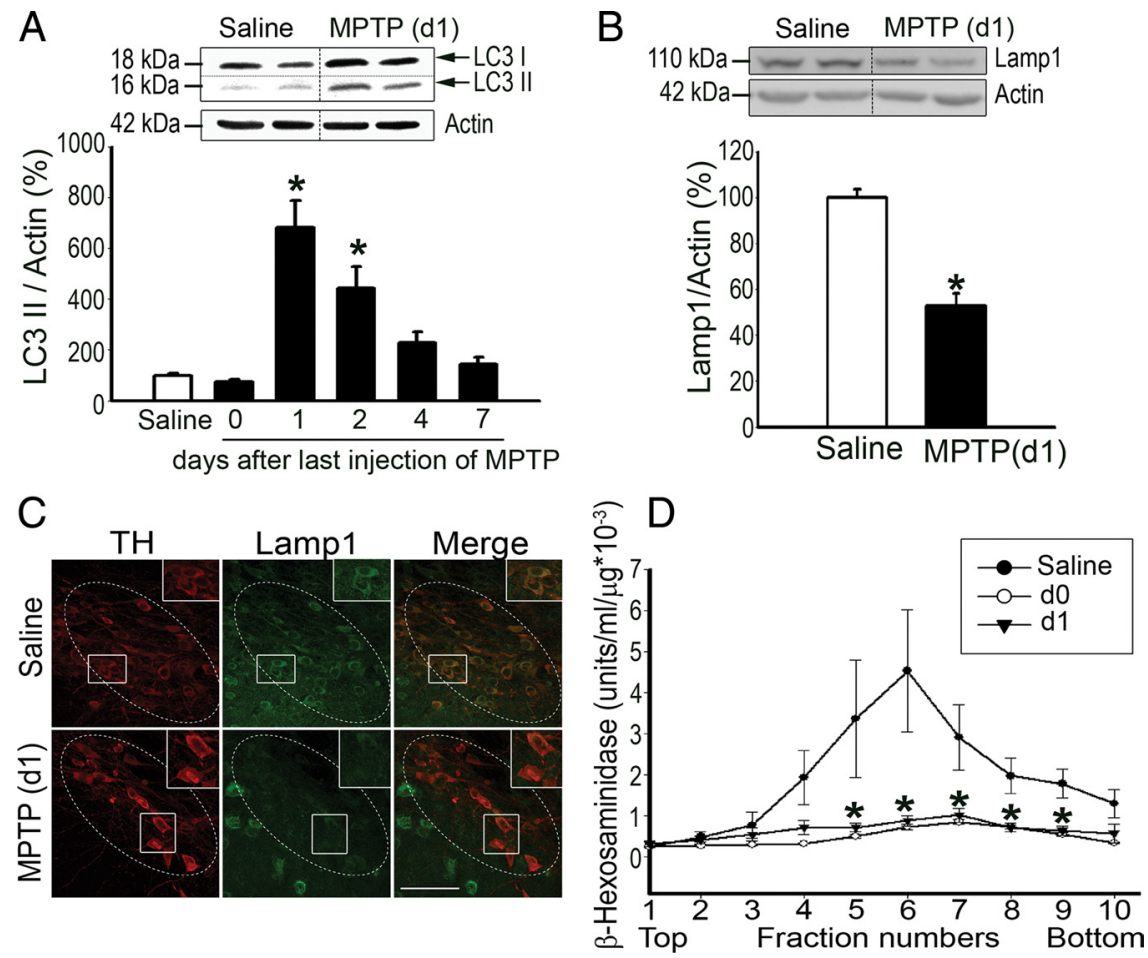

Figure 1. Lysosomal depletion and AP accumulation in MPTP-intoxicated mice. $\boldsymbol{A}, \mathrm{LC} 3 \mathrm{ll}$ immunoblot levels in ventral midbrain protein homogenates from saline- and MPTP-injected mice. $\boldsymbol{B}$, Immunoblot Lamp1 levels in ventral midbrain protein homogenates from saline- and MPTP-injected mice at day 1 post-MPTP. C, Double immunofluorescence with Lamp1 (green) and TH (red) in ventral midbrain sections of saline- and MPTP-injected mice at day 1 post-MPTP. $\boldsymbol{D}, \beta$-Hexoaminidase enzymatic activity in ventral midbrain lysosomal-enriched fractions (fractions 5, 6, and 7) from saline- and MPTP-injected mice at day 0 and day 1 post-MPTP. In all experiments, $n=5-7$ animals per experimental group. ${ }^{*} p<0.05$ compared with saline-injected mice. In $\boldsymbol{C}$, white dotted line delimits SNpc. Scale bar, $10 \mu \mathrm{m}$.

University of Barcelona Brain Bank and the Madrid Brain Bank. Substantia nigra was dissected from ventral midbrain samples from 3-14 control subjects and 9-17 PD patients, matched for age and postmortem delay, as follows: (1) age at death, in years (control subjects, 68.21 \pm 4.77 ; PD patients, 77.29 \pm 1.75 ); (2) cold postmortem interval, in hours (control subjects, $6.04 \pm 0.75$; PD patients, $6.27 \pm 1.07$ ); (3) frozen postmortem interval, in hours (control subjects, $12.67 \pm 2.41 ; \mathrm{PD}$ patients, $14.98 \pm 2.06$ ). Total proteins were isolated as mentioned above. For Western blot analyses, incubation with primary antibodies was performed overnight at $4^{\circ} \mathrm{C}$ with antibodies against Lamp1 (1: 1000; GeneTex) and LC3 (1:1000; Novus Biologicals). Actin (1:5000, Sigma) or tubulin (1:1000; Sigma) were used as loading controls. For immunohistochemical analyses, paraffin-embedded ventral midbrain blocks from 9 control subjects and 9 PD patients were cut at 5 $\mu \mathrm{m}$. Following antigen retrieval with citrate buffer, sections were incubated overnight at $4^{\circ} \mathrm{C}$ with antibodies against Lamp1 (1:1000; GeneTex) or LC3 (1:1000; Novus Biologicals). Vector SG substrate kit or DAB were used as chromogens.

Statistical analysis. All values are expressed as the mean \pm SEM. Differences among means were analyzed with one-way ANOVA. When ANOVA showed significant differences, pair wise comparisons between means were tested by Student-Newman-Keuls post hoc testing. In all analyses, the null hypothesis was rejected at the 0.05 level.

\section{Results}

Lysosomal depletion precedes AP accumulation and dopaminergic neurodegeneration in the MPTP mouse model of PD

Mitochondrial parkinsonian neurotoxin MPTP reproduces several PD-linked cellular alterations, such as inhibition of mitochondrial complex I, increased production of reactive oxygen species (ROS), oxidative damage to lipids, DNA and proteins, including $\alpha$-synuclein, activation of mitochondriadependent apoptotic pathways and dopaminergic cell death (Mandir et al., 1999; Vila et al., 2001, 2008; Dauer and Przedborski, 2003; Vila and Przedborski, 2003; Perier et al., 2005, 2007). Here we found that MPTP (30 mg/kg/d for five consecutive days) induced a time-dependent accumulation of $\mathrm{AP}$ in the ventral midbrain of intoxicated mice, as indicated by increased protein levels of the AP marker LC3II in these animals (Fig. 1A). LC3II protein levels peaked at day 1 post-MPTP, preceding dopaminergic cell death in this model, which occurs between days 2 and 4 after the last MPTP injection (Vila et al., 2001; Perier et al., 2005, 2007). After its peak, LC3II levels decreased progressively in parallel to the gradual loss of dopaminergic neurons (Fig. $1 A$ ).

Because LC3II is normally degraded by lysosomal proteases once the AP fuses with a lysosome to form an autophagolysosome (Mizushima and Yoshimori, 2007), the accumulation of LC3II protein observed following MPTP intoxication indicates that, in addition to any potential induction of new AP formation, the lysosomalmediated clearance of AP is impaired in these animals. Supporting the latter, the levels of the lysosomal structural protein Lamp1, which is abundantly localized in the limiting membrane of the organelle, were markedly decreased in the ventral midbrain of MPTP-intoxicated mice at the peak of MPTPinduced AP accumulation (Fig. $1 B$ ). Double immunofluorescence examination revealed that Lamp1 reductions occurred within SNpc dopaminergic neurons in these animals (Fig. 1C). Decreased Lamp1 levels following MPTP intoxication could not be simply attributed to a reduced number of dopaminergic cells in these animals, as it occurred prior dopaminergic cell death, nor to a transcriptional downregulation, as Lamp1 mRNA expression levels were unchanged following MPTP intoxication (supplemental Fig. $1 A$, available at www.jneurosci.org as supplemental material). Instead, it corresponded to a decreased number of lysosomes in these animals, as lysosomal purification experiments revealed a severe reduction of lysosomal contents in the ventral midbrain of MPTP-intoxicated mice (Fig. 1D). Lysosomal depletion was already observed at day 0 post-MPTP, thus preceding the accumulation of AP in this model (Fig. 1D). These results indicate that the number of lysosomes is decreased in SNpc dopaminergic neurons early following MPTP intoxication, within a time-frame compatible with these changes to influence the fate of dopaminergic neurons in this pathological situation.

\section{Lysosomal depletion occurs in $\mathrm{MPP}^{+}$-treated dopaminergic cells}

To explore the molecular mechanisms and pathogenic significance of MPTP-induced lysosomal deficiency, additional experiments were performed in human dopaminergic BE-M17 neuroblastoma cells intoxicated with parkinsonian neurotoxin $\mathrm{MPP}^{+}$, the active metabolite of MPTP. As similarly observed in MPTP-intoxicated mice, Lamp1 protein levels were decreased in 

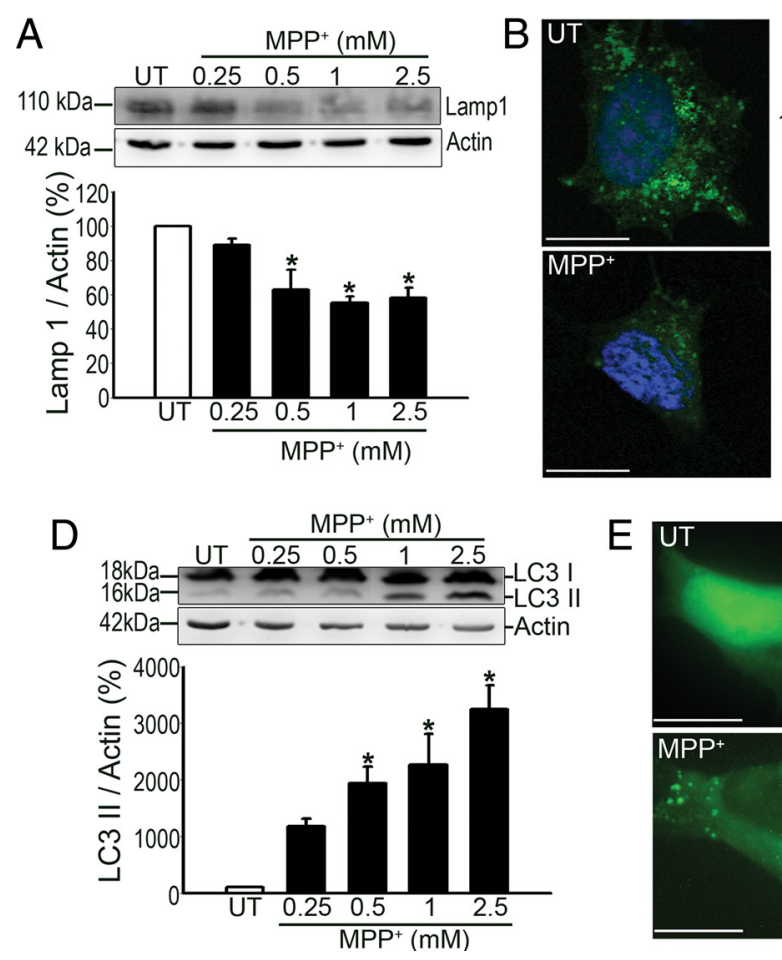
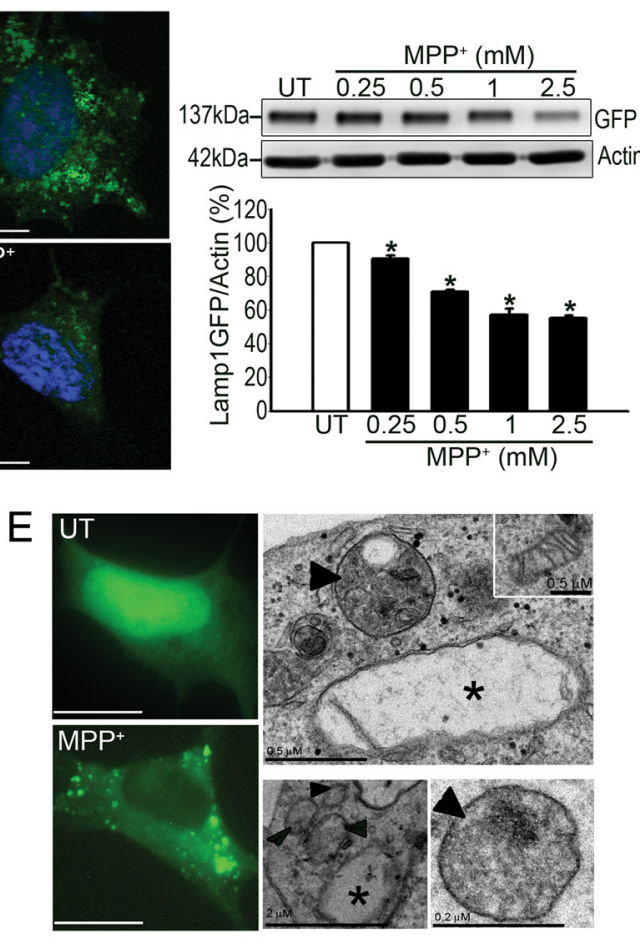
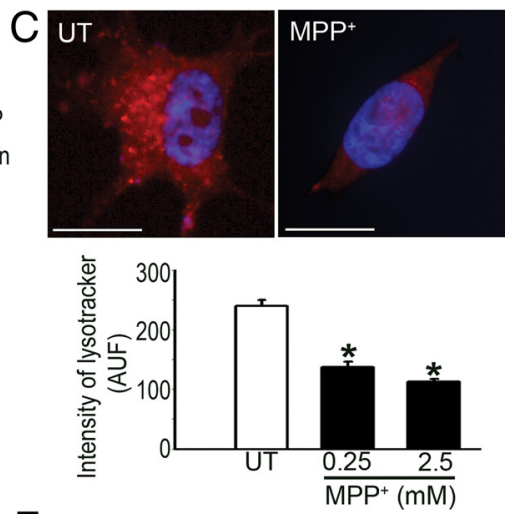

$\mathrm{F}$

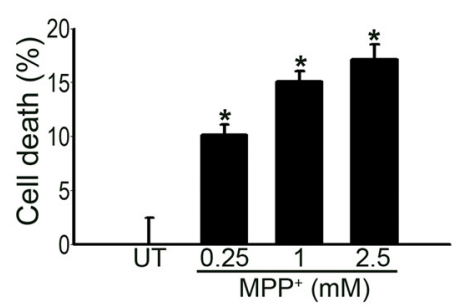

Figure 2. Lysosomal depletion and AP accumulation in $\mathrm{MPP}^{+}{ }^{+}$-treated cells. $A$, Lamp1 immunoblot levels in human dopaminergic BE-M17 neuroblastoma cells intoxicated with different doses of MPP ${ }^{+}$for 24 h. B, Left, Lamp1-GFP fluorescent signal (green; nucleus in blue) in untreated (UT) and MPP ${ }^{+}$-intoxicated transfected cells. B, Right, GFP immunoblot levels in UT and MPP ${ }^{+}$. intoxicated Lamp1-GFP-transfected cells. C, Top, LysoTracker fluorescent pattern (red; nucleus in blue) in UT and MPP ${ }^{+}$-intoxicated cells. C, Bottom, Intensity of LysoTracker fluorescent signal in UT and $\mathrm{MPP}^{+}{ }^{-}$-intoxicated cells, quantified by flow cytometry. $\mathbf{D}, \mathrm{LC} 3 \mathrm{ll}$ immunoblot levels in UT and MPP ${ }^{+}$-intoxicated cells. $\boldsymbol{E}$, Left, GFP-LC3 fluorescent signal (green) in UT and MPP ${ }^{+}$-intoxicated transfected cells. $\boldsymbol{E}$, Right, Electron microscopy images from $\mathrm{MPP}^{+}$-intoxicated cells (arrowheads, AP; asterisks, abnormal mitochondria; inset, normal mitochondria). $\boldsymbol{F}$, Cell death in UT and

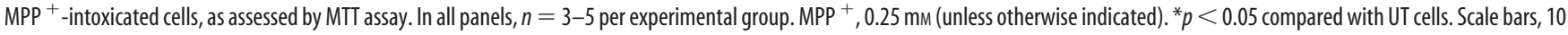
$\mu \mathrm{m}$ (unless otherwise indicated).

a dose-dependent manner in $\mathrm{MPP}^{+}$ treated cells (Fig. $2 A$ ), without concomitant decreases in mRNA expression levels (supplemental Fig. 1A, available at www. jneurosci.org as supplemental material). Using a Lamp1-GFP construct, Lamp1GFP levels appeared decreased in the cytosol of transfected cells following MPP ${ }^{+}$ intoxication (Fig. 2B). Decreased Lamp1 levels in $\mathrm{MPP}^{+}$-intoxicated cells corresponded to a decreased number of lysosomes, as these cells exhibited a reduced intensity of the fluorescent signal emitted by the lysosomotropic fluorochrome LysoTracker, as quantified by flow cytometry, and a redistribution of the LysoTracker fluorescent pattern from punctuate to markedly diffuse (Fig. 2C).

In parallel to $\mathrm{MPP}^{+}$-induced lysosomal deficiency, $\mathrm{MPP}^{+}$-treated cells exhibited a dose-dependent accumulation of undegraded AP, as indicated by increased LC3II levels by immunoblot (Fig. 2D). The accumulation of AP following $\mathrm{MPP}^{+}$ intoxication was confirmed by the observation of GFP-LC3-positive AP in transfected cells (Fig. 2E). Electron microscopy examination of $\mathrm{MPP}^{+}$-treated cells revealed the presence of abundant abnormal mitochondria exhibiting a loss of
A

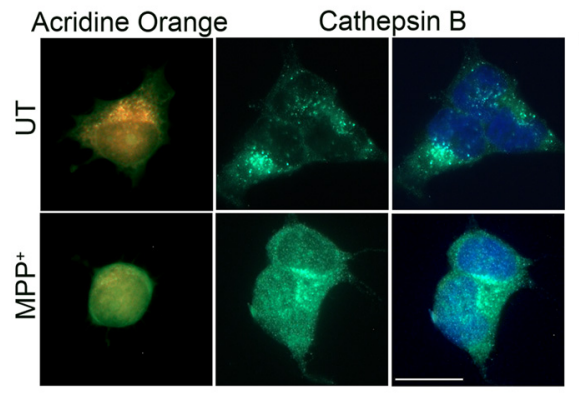

B
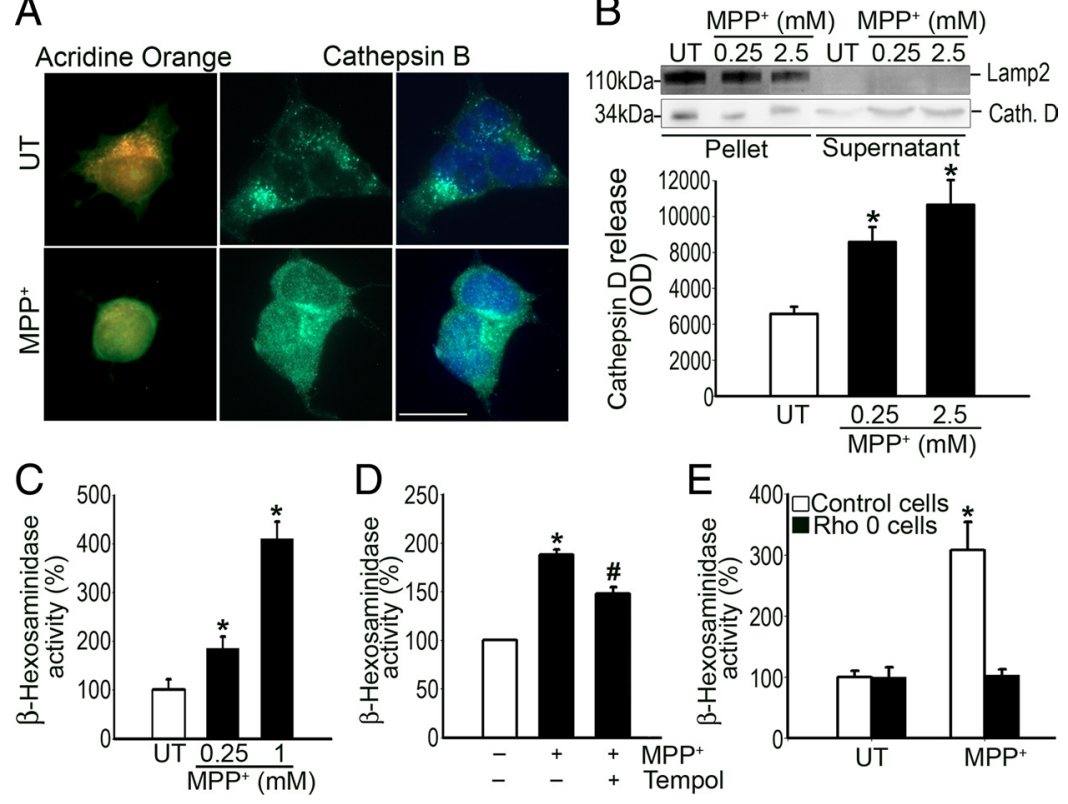

Figure 3. Lysosomal membrane permeabilization in $\mathrm{MPP}^{+}$-treated cells. $A$, Left, Acridine orange fluorescent signal in UT and $\mathrm{MPP}^{+}{ }^{-}$-intoxicated cells. $A$, Right, Cathepsin B immunofluorescent signal (green; nuclei in blue) in UT and MPP ${ }^{+}$-intoxicated cells. $B$, Cathepsin D immunoblot levels in pellet and supernatant lysosomal fractions from UT and MPP ${ }^{+}$-intoxicated cells. Lamp2 was used as a lysosomal marker. $C, \beta$-Hexosaminidase enzymatic activity in lysosomal-free cytosolic fractions from UT and MPP ${ }^{+}$. intoxicated cells. $\boldsymbol{D}, \beta$-Hexosaminidase enzymatic activity in lysosomal-free cytosolic fractions from UT and MPP ${ }^{+}$-intoxicated cells, treated or not with tempol (500 $\mu \mathrm{m}$ for $24 \mathrm{~h}$ ). $\boldsymbol{E}, \beta$-Hexosaminidase enzymatic activity in lysosomal-free cytosolic fractions from UT and MPP ${ }^{+}$-intoxicated Rho0 and control cells. In all panels, $n=3-5$ per experimental group. MPP ${ }^{+}, 0.25 \mathrm{~mm}$ (unless otherwise indicated). ${ }^{*} p<0.05$ compared with UT cells. ${ }^{\#} p<0.05$ compared with MPP ${ }^{+}$-treated cells. Scale bar, $10 \mu \mathrm{m}$. 
A
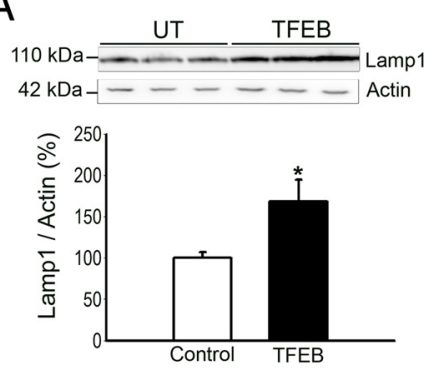

B

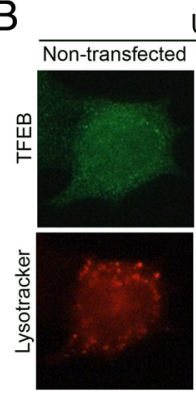

F GFPLC3

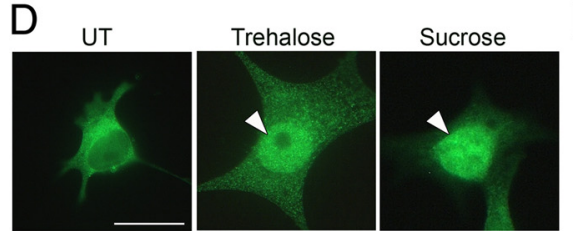

$\mathrm{E}$

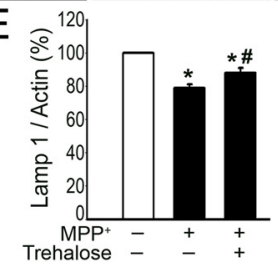

UT

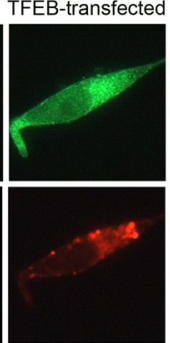

RFPLC3

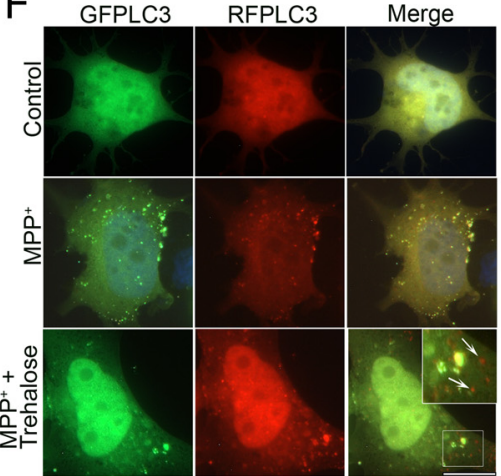

$\mathrm{MPP}^{+}$
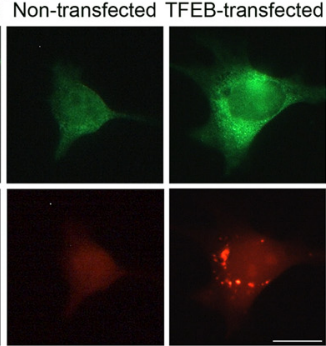

G

C
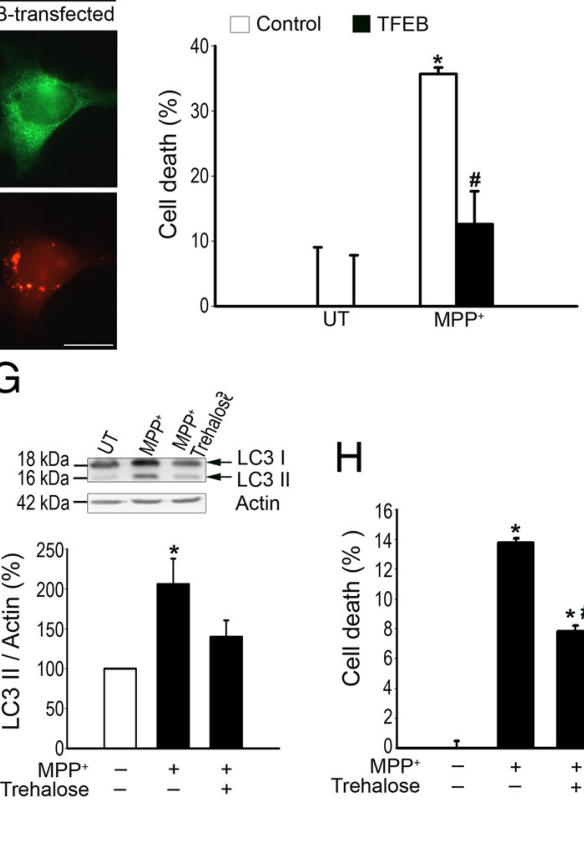

$\mathrm{H}$

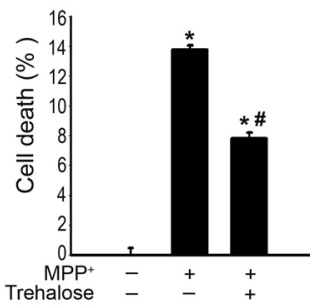

Figure 4. Enhancement of lysosomal biogenesis by TFEB attenuates MPP ${ }^{+}$-induced cell death. $A$, Lamp1 immunoblot levels in control or TFEB-transfected cells. $B$, LysoTracker fluorescent signal (red) in control or TFEB-transfected cells, UT or intoxicated with MPP ${ }^{+}$. In transfected cells, TFEB is detected by immunofluorescence (green). C, Cell death in control or TFEB-transfected cells, UT or intoxicated with $\mathrm{MPP}^{+}$, as assessed by MTT assay. D, TFEB immunofluorescence (green) in nontransfected cells, UT or treated with trehalose (1 mM) or sucrose (100 mM) for $24 \mathrm{~h}$. $\boldsymbol{E}$, Lamp1 immunoblot levels in UT and MPP ${ }^{+}$-intoxicated nontransfected cells, treated or not with trehalose. $\boldsymbol{F}$, Fluorescent signal of GFP-LC3 (green) and RFP-LC3 (red) in UT and MPP ${ }^{+}$-intoxicated tfLC3-transfected cells, treated or not with trehalose (arrows indicate autophagolysosomes, visualized as red-only structures). G, LC3Il immunoblot levels in UT and MPP ${ }^{+}$-intoxicated cells, treated or not with trehalose. $\boldsymbol{H}$, Cell death in UT and MPP ${ }^{+}$-intoxicated cells, treated or not with trehalose, as assessed by MTT assay. In all panels, $n=3-5$ per experimental group. MPP ${ }^{+}, 0.25 \mathrm{~mm}$, unless otherwise indicated. ${ }^{*} p<0.05$ compared with UT cells. \#p $<0.05$ compared with MPP ${ }^{+}$-treated cells. Scale bar, $10 \mu \mathrm{m}$.

matrix density, cristae disruption and swelling, close to which numerous AP could be identified as double-membrane limited structures containing intact or partly degraded cytoplasmic material (Fig. 2E). Lysosomal deficiency and accumulation of AP in $\mathrm{MPP}^{+}$-treated cells were associated with increased cell death (Fig. $2 \mathrm{~F}$ ). The occurrence of $\mathrm{MPP}^{+}$-induced lysosomal depletion, AP accumulation and cell death was also observed in primary mesencephalic dopaminergic neurons (supplemental Fig. 2A,B). These results indicate that decreased lysosomal contents and defective clearance of $\mathrm{AP}$ also occur in an in vitro paradigm of $\mathrm{PD}$, setting the stage for the use of this experimental cellular model to further explore the mechanism and pathogenic significance of PD-related lysosomal depletion.

\section{Lysosomal membrane permeabilization in $\mathrm{MPP}^{+}$-treated cells}

To determine the mechanism underlying lysosomal deficiency following $\mathrm{MPP}^{+}$intoxication, we assessed the occurrence of lysosomal membrane permeabilization (LMP) in this cellular model, as LMP has been linked to lysosomal breakdown and cell death in other experimental paradigms (Boya and Kroemer, 2008). Acridine orange (AO) is a lysosomotropic metachromatic fluorochrome that accumulates in lysosomes, from where it emits an intense orange fluorescent signal (Fig. 3A). Supporting the occurrence of LMP following $\mathrm{MPP}^{+}$intoxication, AO fluorescent signal was markedly reduced, indicating lysosomal disruption (Fig. $3 A$ ). Another distinctive sign of LMP is the translocation of soluble lysosomal components, such as cathepsins and other lysosomal hydrolases, from the lysosomal lumen to the cytosol (Boya et al., 2003). Untreated cells exhibited a cytoplasmic punctuate distribution pattern of Cathepsin $\mathrm{B}(\mathrm{CB})$ at confocal microscopy examina- tion, indicative of its localization within lysosomes (Fig. 3A). Following $\mathrm{MPP}^{+}$intoxication, the distribution pattern of $\mathrm{CB}$ became widely diffuse throughout the entire cell, indicating a redistribution of $\mathrm{CB}$ from lysosomes to the cytosol (Fig. 3A). Similarly, subcellular fractionation studies revealed a release of cathepsin D (CD) from purified lysosomes in $\mathrm{MPP}^{+}$-treated cells (Fig. $3 B$ ). Further supporting the occurrence of LMP, the activities of two lysosomal enzymes, $\beta$-hexosaminidase and acid phosphatase, were increased in a dose-dependent manner in the cytosolic fractions of $\mathrm{MPP}^{+}$-treated cells, after removing lysosomes by differential centrifugation (Fig. $3 C$; supplemental Fig. $3 A$, available at www.jneurosci.org as supplemental material). In addition to impairing lysosomal-mediated degradation, LMP can directly contribute to cell death because of the ectopic release of lysosomal proteases to the cytosol (Boya and Kroemer, 2008). In agreement with this, pharmacological inhibition of CD and CB significantly attenuated $\mathrm{MPP}^{+}$-induced cell death (supplemental Fig. $1 C$, available at www.jneurosci.org as supplemental material).

\section{LMP linked to complex I inhibition is mediated by} mitochondrial-derived ROS

Among the different stimuli that can induce LMP, ROS are the most frequently implicated (Boya and Kroemer, 2008). Because enhanced ROS production is a major pathogenic feature of $\mathrm{MPTP} / \mathrm{MPP}^{+}$-induced dopaminergic neurotoxocity and PD (Dauer and Przedborski, 2003; Perier et al., 2005), we determined whether increased ROS production was responsible for LMP following MPP ${ }^{+}$intoxication. Supporting the latter hypothesis, $\mathrm{MPP}^{+}$-induced LMP in M17 cells was attenuated by tempol, a free radical scavenger and superoxide dismutasemimetic compound (Fig. 3D; supplemental Fig. 3B, available 
at www.jneurosci.org as supplemental material). Attenuation of $\mathrm{MPP}^{+}$-induced LMP with tempol was associated with reduced cell death (supplemental Fig. 1C, available at www.jneurosci.org as supplemental material). Furthermore, ROS derived from the mitochondria appeared to be, in particular, at the origin of $\mathrm{MPP}^{+}$-induced LMP, as MPP ${ }^{+}$was unable to permeabilize lysosomes in Rho0 cells, devoid of functional mitochondria (Fig. 3E; supplemental Fig. 3C, available at www.jneurosci.org as supplemental material). Because weakly basic lysosomotropic amines such as ammonium chloride are known to induce LMP by alkalinizing the intralysosomal acidic pH (Boya and Kroemer, 2008) and $\mathrm{MPP}^{+}$is a quaternary ammonium compound able to alkalinize intracellular $\mathrm{pH}$ in some cellular settings (Dudley et al., 2000), we ruled out the possibility that $\mathrm{MPP}^{+}$could directly induce LMP (supplemental Fig. 4D,E, available at www.jneurosci.org as supplemental material).

\section{Enhancement of lysosomal biogenesis} in $\mathrm{MPP}^{+}$-intoxicated cells restores lysosomal levels, increases AP clearance, and attenuates cell death Because $\mathrm{MPP}^{+}$-induced lysosomal deficiency is associated with cell death, we next determined whether restoration of lysosomal levels can attenuate cell loss in this pathological situation. The transcription factor EB (TFEB) was recently identified as an enhancer of lysosomal biogenesis by inducing the coordinated expression of several lysosomal-related genes, including Lamp1 (Sardiello et al., 2009). In agreement with this, M17 cells transfected with a TFEB plasmid exhibited increased protein levels of Lamp1 compared with nontransfected cells (Fig. 4A; supplemental Fig. $1 B$, available at www.jneurosci.org as supplemental material). Remarkably, TFEB overexpression reversed $\mathrm{MPP}^{+}$-induced lysosomal depletion, as indicated by preserved LysoTracker fluorescent signal in transfected cells (Fig. 4B), and attenuated $\mathrm{MPP}^{+}$-induced cell death (Fig. 4C).

The common disaccharide sucrose is known to activate TFEB and upregulate lysosomal-related genes in cell culture (Karageorgos et al., 1997; Helip-Wooley and Thoene, 2004; Sardiello et al., 2009). Trehalose, a disaccharide homologous to sucrose, has been recently reported to accelerate the clearance of mutant huntingtin and $\alpha$-synuclein and to protect cultured neurons against mitochondria-dependent apoptotic insults by inducing autophagy (Sarkar et al., 2007). Here we found that, similar to sucrose, trehalose is able to activate TFEB, as indicated by the nuclear translocation of TFEB in trehalose-treated cells (Fig. 4D). In $\mathrm{MPP}^{+}$-intoxicated cells, trehalose significantly increased Lamp1 protein levels (Fig. 4E), indicative of enhanced lysosomal contents in these cells. Accordingly, $\mathrm{MPP}^{+}$-intoxicated cells treated with trehalose exhibited increased autophagolysosome formation, indicative of increased fusion of AP with lysosomes, as determined by using a tfLC3 construct that allows the distinction between AP and autophagolysosomes (Fig. 4F). Cells transfected with tfLC3 exhibited a marked accumulation of AP following $\mathrm{MPP}^{+}$intoxication, as indicated by the presence of colocalized green/red-labeled vacuoles in their cytosol (Fig. $4 F$ ). In these cells, treatment with trehalose induced the formation of autophagolysosomes, as visualized by the presence of red-only labeled vacuoles because of the degradation of GFP-LC3 during the fusion of AP with lysosomes (Fig. 4F) (Kimura et al., 2007). Increased autophagolysosome formation with trehalose resulted in increased clearance of AP, as indicated by an attenuation of $\mathrm{MPP}^{+}$-induced LC3II accumulations by immunoblot (Fig. 4G), and was associated to a marked attenuation of $\mathrm{MPP}^{+}$-induced cell death (Fig. $4 H$ ).

Rapamycin protects against PD-related dopaminergic neurodegeneration in vitro and in vivo by enhancing lysosomal biogenesis and AP clearance

Rapamycin is a Food and Drug Administration (FDA)-approved antibiotic and immunosuppressant that inhibits the activity of mTOR (mammalian target of rapamycin) and, as such, is one of the few pharmacological molecules known to induce autophagy (Sarkar et al., 2009). Rapamycin has been shown to protect against mutant huntingtin-induced neurodegeneration in cellular and animal models of Huntington's disease through autoph- 
A
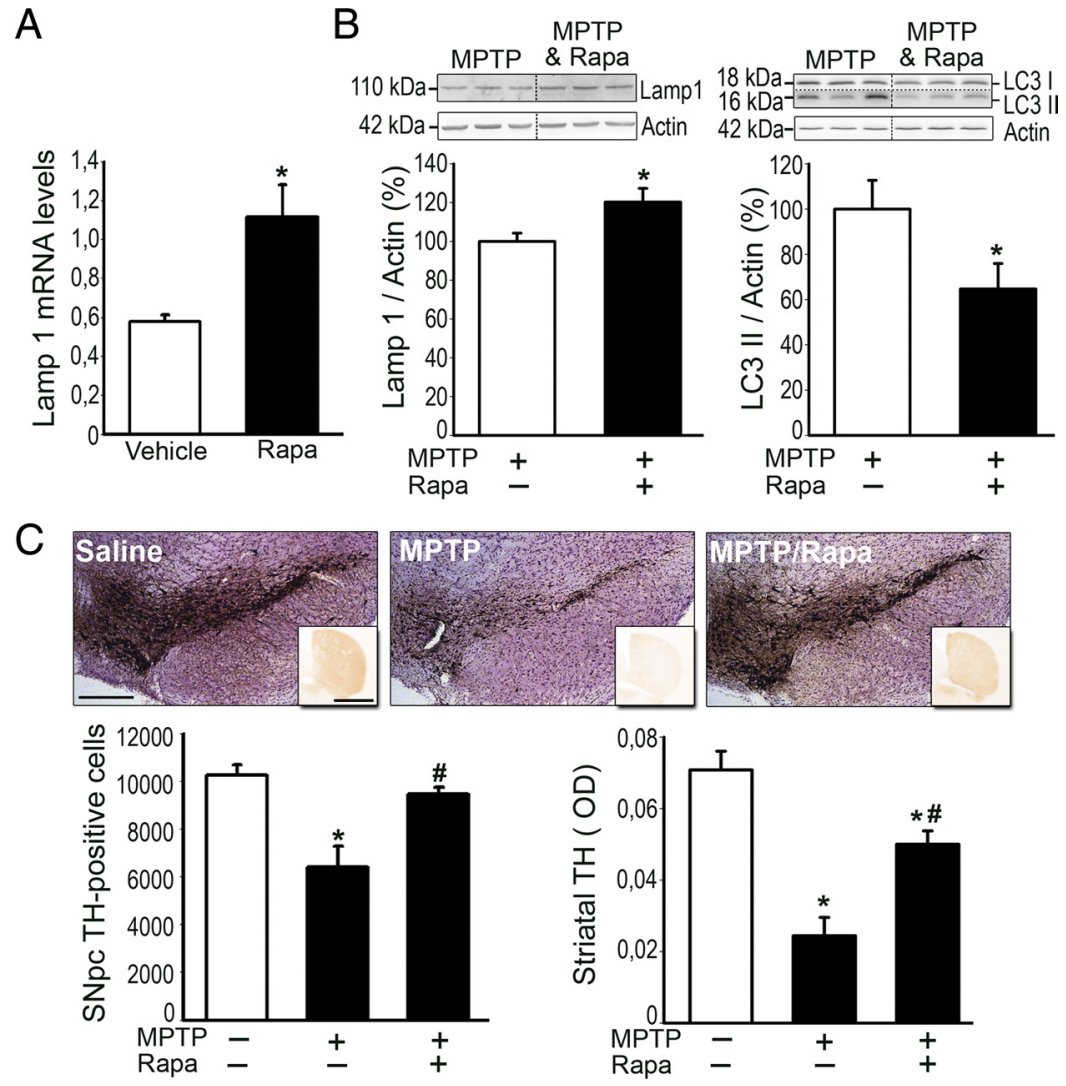

Figure 6. Rapamycin attenuates MPTP-induced dopaminergic neurodegeneration in vivo by enhancing lysosomal biogenesis and AP clearance. $\boldsymbol{A}$, Lamp1 mRNA levels in ventral midbrain homogenates from vehicle- or rapamycin-injected mice (i.p., 7.5 $\mathrm{mg} / \mathrm{kg} / \mathrm{d}$ for seven consecutive days; $n=5$ animals per group). ${ }^{*} p<0.05$ compared with vehicle-injected mice. $\boldsymbol{B}$, Lamp1 and LC3II immunoblot levels in MPTP-intoxicated mice, treated or not with Rapamycin, at day 1 post-MPTP $(n=9$ for MPTPintoxicated mice, $n=8$ for MPTP + rapamycin-treated animals). ${ }^{*} p \leq 0.05$ compared with MPTP-intoxicated mice. C, Stereological cell counts of SNpc TH-immunoreactive neurons (left panel) and optical densitometry of striatal TH immunoreactivity (right panel) from saline- or MPTP-intoxicated mice, treated or not with rapamycin, at day 21 post-MPTP ( $n=9$ for vehicle-injected animals, $n=10$ for MPTP-treated mice, and $n=15$ for MPTP + rapamycin-treated animals). Top panels display representative photomicrographs of TH-immunostained SNpc (brown; thionin in blue) and striatum (inset) in these animals. ${ }^{*} p<0.05$ compared with vehicle-injected mice, ${ }^{\#} p<0.05$ compared with MPTP-intoxicated mice.

agy enhancement (Ravikumar et al., 2004). In the context of PD, rapamycin has been shown to attenuate dopaminergic cell death induced by PD-related gene mutants in Drosophila or by MPTP in mice (Tain et al., 2009; Malagelada et al., 2010). In the latter reports, however, a potential involvement of autophagy-related pathways on rapamycin neuroprotective effects were not, or only partially, explored. Here we found that rapamycin increased Lamp1 levels and LysoTracker fluorescent signal in $\mathrm{MPP}^{+}$. intoxicated cells (Fig. 5A,B), indicative of increased lysosomal biogenesis in these cells. Accordingly, $\mathrm{MPP}^{+}$-intoxicated cells treated with rapamycin exhibited increased autophagolysosome formation, as determined using a tfLC3 construct (Fig. 5C), and increased clearance of AP, as indicated by an attenuation of LC3II accumulations (Fig. 5D), all of which resulted in an attenuation of $\mathrm{MPP}^{+}$-induced cell death (Fig. 5D). The neuroprotective effects of rapamycin were also confirmed in $\mathrm{MPP}^{+}$-intoxicated primary mesencephalic dopaminergic neurons (supplemental Fig. 2C, available at www.jneurosci.org as supplemental material). Remarkably, rapamycin was also able to increase lysosomal levels in vivo, as indicated by increased Lamp1 levels in the ventral midbrain of rapamycin-treated mice (Fig. 6A). In MPTPintoxicated mice, rapamycin treatment restored lysosomal levels and attenuated AP accumulation (Fig. 6B), which was associated to an attenuation of dopaminergic neurodegeneration in these animals, both at the level of SNpc dopaminergic neuron cell bodies and striatal dopaminergic terminals (Fig. 6C).

Our results indicate that, in addition to any potential effects on AP formation (Sarkar et al., 2009), rapamycin exerts part of its proautophagy actions by increasing lysosomal biogenesis and enhancing lysosomal-mediated clearance, all of which contribute to the neuroprotective effects of this compound on PDrelated dopaminergic neurodegeneration.

\section{Lysosomal deficiency, AP accumulation, and LC3-positive Lewy bodies in the SNpc of PD patients}

Supporting the relevance of our experimental results to $\mathrm{PD}$, decreased lysosomal markers and accumulation of AP-like structures have been observed in postmortem PD brain samples (Y. Chu et al., 2009). Extending these observations, here we found that postmortem nigral samples from PD patients exhibited marked decreases in Lamp1 protein levels by immunoblot, compared with age-matched control subjects (Fig. 7A). Immunohistochemical examination of the SNpc of PD patients indicated that reductions in Lamp1 occurred in the cytosol of melanized dopaminergic neurons (Fig. $7 A$ ). In parallel to reduced Lamp1 levels, immunoblot levels of LC3II were markedly increased in PD nigral samples (Fig. $7 B$ ). Furthermore, immunohistochemical studies identified LC3 as a major component of Lewy bodies (Fig. 7C-H). In the SNpc of PD patients, $\sim 80 \%$ of Lewy bodies were strongly immunoreactive for LC3, especially in its halo, where it colocalized with $\alpha$-synuclein (Fig. 7C-H). In addition, strong LC3 immunoreactivity was also detected in $\alpha$-synuclein-positive Lewy neurites, a neuropathological feature of PD indicative of axonal pathology (Fig. $7 I-K)$. In contrast, no LC3 immunostaining was detected in control experiments omitting the primary antibody (supplemental Fig. 4, available at www.jneurosci.org as supplemental material). Our results confirm that lysosomal depletion and defective clearance of AP also occur in PD patients.

\section{Discussion}

On the basis of our results, we propose here a novel pathogenic mechanism contributing to PD-related dopaminergic neurodegeneration. In this scenario, enhanced mitochondrial-derived ROS secondary to PD-linked mitochondrial dysfunction induces the abnormal permeabilization of lysosomal membranes and subsequent disruption of lysosomal structural integrity. Lysosomal breakdown, in turn, results in a defective clearance and subsequent accumulation of undegraded AP, which may be further enhanced by new AP formation in this pathological situation, in agreement with the known effects of mitochondrial dysfunction and ROS on autophagy induction (Scherz-Shouval and Elazar, 2007; Narendra et al., 2008; Vives-Bauza et al., 2010). In addition to overload- 
ing the system with undegraded AP, damaged proteins and altered organelles, such as mitochondria, lysosomal deficiency can contribute to neuron cell death by the ectopic release of lysosomal proteases into the cytosol, some of which, such as $\mathrm{CB}$ and $\mathrm{CD}$, can remain active at neutral $\mathrm{pH}$ and cause the digestion of vital proteins, the activation of additional hydrolases, including caspases, or the recruitment of the proapoptotic protein Bax to the mitochondria (Boya and Kroemer, 2008). In addition, accumulation of undegraded AP may eventually contribute to cell dysfunction/death by occupying a large portion of the neuron cell body and interfering with cellular functions (Sulzer et al., 2008). The lysosomal depletion reported here cannot simply be regarded as a generalized response to cell distress/death, since: (1) it was not observed using other cellular insults, such as proapoptotic TNF $\alpha$ /actinomycin D (supplemental Fig. 5, available at www.jneurosci.org as supplemental material), or in other neurodegenerative conditions, such as Alzheimer's disease (Barrachina et al., 2006), (2) it preceded the activation of molecular pathways of apoptosis and dopaminergic cell death in experimental models of PD, and (3) its genetic or pharmacological restoration attenuated PD-related neurodegeneration.

The identification of LC3 as a major component of Lewy bodies raises the possibility that Lewy bodies, which origin and significance are currently unknown, may derive from accumulated undegraded AP. Further supporting the latter possibility, (1) ultrastructural studies indicate that membrane-limited AP can evolve into more mature condensed inclusion bodies, more closely resembling Lewy bodies, in which no longer membranous structures appear (Castino et al., 2008); (2) some pathological studies remarked the rather vesicular nature of Lewy bodies in PD, suggesting the participation of the autophagylysosomal pathway in the formation of these inclusions (Forno and Norville, 1976); (3) nigral Lewy bodies are closely associated with neuromelanin granules, the latter arising from incompletely degraded AP (Tribl et al., 2006); (4) ubiquitin, which is a main component of Lewy bodies and is commonly associated with proteasome degradation pathways, can also target cytosolic components for its autophagic degradation (Kim et al., 2008); (5) Lewy bodies contain abnormal mitochondria and autophagyrelated molecules (Shults, 2006); and (6) LC3-II protein levels are also increased in postmortem cortical tissue from patients with Dementia with Lewy bodies (Yu et al., 2009), a disease that exhibits $\alpha$-synuclein-positive Lewy bodies similar to those found in PD. Further supporting a role for defective lysosomal-mediated cellular clearance in Lewy body formation and PD-related cell death, (1) some patients with Gaucher disease, the most common lysosomal storage disorder resulting from the inherited deficiency of the lysosomal enzyme glucocerebrosidase, exhibit clinical parkinsonism and $\alpha$-synuclein-immunoreactive Lewy bodies (Aharon-Peretz et
B
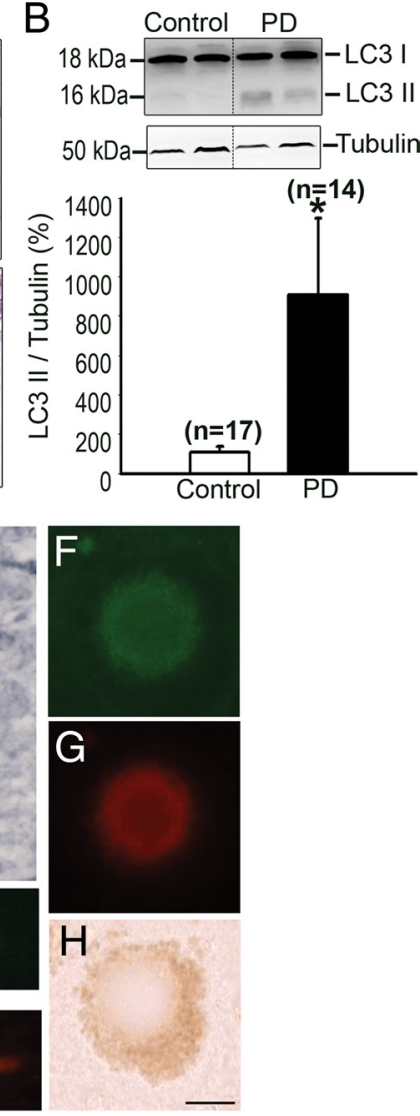
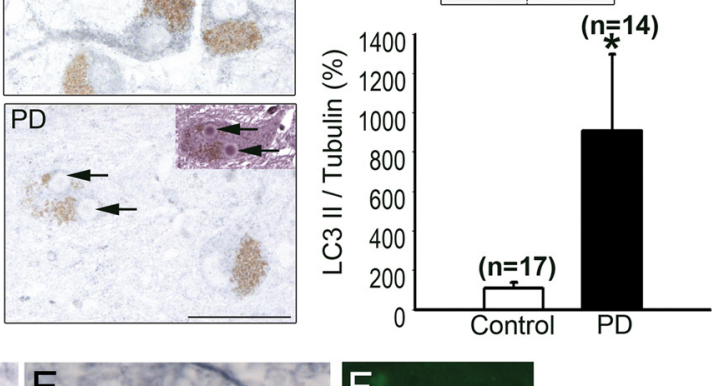

Figure 7. Lysosomal depletion and AP accumulation in postmortem PD samples. $\boldsymbol{A}$, Left, Lamp1 immunoblot levels in postmortem substantia nigra protein homogenates from PD patients and age-matched control subjects. $\boldsymbol{A}$, Right, Lamp1 immunostaining (blue; brown pigment corresponds to neuromelanin) in postmortem substantia nigra sections from PD patients and

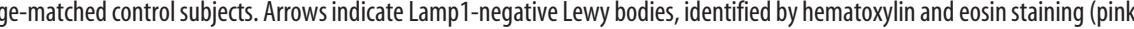
G). In $\boldsymbol{H}$, brown pigment corresponds to neuromelanin in transmitted light. $\mathbf{I}-\boldsymbol{K}, \mathrm{LC} 3$ immunoreactivity was also detected in Lewy neurites in postmortem substantia nigra sections from PD patients (I, LC3 in brown; $\boldsymbol{J}, \boldsymbol{K}, \mathrm{LC} 3$ in green, $\alpha$-synuclein in red). In all panels, ${ }^{*} p<0.05$ compared with age-matched control subjects. Scale bars, $10 \mu \mathrm{m}$.

al., 2004); (2) patients with PD have an increased prevalence of mutations in the lysosomal glucocerebrosidase gene (AharonPeretz et al., 2004); (3) glucocerebrosidase mutations are also an important risk factor for other Lewy bodies disorders, such as dementia with Lewy bodies (Goker-Alpan et al., 2006); (4) mutations in a lysosomal type 5 P-type ATPase have been associated with hereditary parkinsonism (Ramirez et al., 2006).

From a therapeutic point of view, our results indicate that genetic or pharmacological enhancement of lysosomal biogenesis and function is able to overcome the deleterious effects associated to lysosomal depletion and may thus represent a novel therapeutic strategy to attenuate neuron cell death in PD. Such approach would reconcile the apparently contradictory reports in the literature suggesting either an inhibition or an activation of autophagy as potentially beneficial strategies against neurodegeneration. Indeed, while most of the literature in the field interprets an increased presence of AP solely as an activation of autophagy, here we demonstrate that, in addition to any potential effects on AP formation, the increased presence of AP in the context of PD results from a defective lysosomal-mediated AP clearance. This concept has important therapeutic implications. If the increased presence of AP associated to neurodegeneration is interpreted as 
a mere activation of autophagy, then strategies aimed at inhibiting autophagy may be envisaged. However, in light of our results, the latter strategy will instead further impair the system. On the other hand, strategies aimed at activating autophagy solely by increasing AP formation, without a concomitant enhancement of lysosomal function, will also result in further cellular damage. We thus propose that therapeutic modulation of autophagy in the context of PD should be aimed at the late steps of the autophagic pathway (i.e., improving the efficiency of AP maturation into autophagolysosomes for subsequent substrate digestion) by boosting lysosomal biogenesis and function.

In this context, we observed that rapamycin, which has been reported to induce autophagy by increasing new AP formation (Sarkar et al., 2009), also exerts part of its proautophagy actions by boosting lysosomal biogenesis and enhancing autophagolysosome formation. These findings are in agreement with previous reports showing rapamycin-induced increases in lysosomal contents and late AP/autophagolysosome formation (Demarchi et al., 2006). In addition, lysosomal biogenesis has been recently identified as part of the cellular response aimed at increasing autophagicmediated cellular clearance (Sardiello et al., 2009). In experimental in vitro and in vivo PD models, rapamycin-induced increases in lysosomal levels resulted in enhanced lysosomal-mediated clearance of AP. While the later results contrast with the reported effects of rapamycin at increasing AP formation, both effects are actually compatible (i.e., rapamycin can induce autophagic degradation both by increasing AP formation and by enhancing autophagolysosome formation and subsequent lysosomal-mediated clearance) and their sequential visualization may depend on the particular kinetics of rapamycin treatment or experimental endpoints. In any event, here we postulate that increased lysosomalmediated clearance induced with rapamycin contributes to the neuroprotective effects of this compound on PD-related dopaminergic neurodegeneration. However, because of the multiplicity of mTOR downstream molecular targets (Foster and Fingar, 2010), it is likely that the neuroprotective effects of rapamycin also involve the inhibition of other mTOR-linked pathways unrelated to autophagy. For instance, it has been reported that rapamycin can block the induction of the pro-cell death molecule RTP801 in MPTP-intoxicated mice (Malagelada et al., 2010) or induce the activation of the pro-survival factor 4E-BP in PDrelated genetic Drosophila models (Tain et al., 2009). While it may be difficult to decipher the individual contribution of the different molecular pathways affected by rapamycin to the overall neuroprotective effect of this compound in experimental PD, our results using mTOR-independent enhancers of lysosomal activation, such as trehalose and TFEB, reinforce the concept that restoration of lysosomal levels and function is indeed able to provide neuroprotection against PD-related dopaminergic neurodegeneration and may thus represent a potentially beneficial new therapeutic strategy for PD. In this context, the identification of a TFEB-mediated cellular program able to enhance lysosomal biogenesis (Sardiello et al., 2009) should open the door to the development of more specific new therapeutic tools selectively aimed at increasing lysosomal activation.

\section{References}

Aharon-Peretz J, Rosenbaum H, Gershoni-Baruch R (2004) Mutations in the glucocerebrosidase gene and Parkinson's disease in Ashkenazi Jews. N Engl J Med 351:1972-1977.

Anglade P, Vyas S, Javoy-Agid F, Herrero MT, Michel PP, Marquez J, MouattPrigent A, Ruberg M, Hirsch EC, Agid Y (1997) Apoptosis and autophagy in nigral neurons of patients with Parkinson's disease. Histol Histopathol 12:25-31.
Barrachina M, Maes T, Buesa C, Ferrer I (2006) Lysosome-associated membrane protein 1 (LAMP-1) in Alzheimer's disease. Neuropathol Appl Neurobiol 32:505-516.

Boya P, Kroemer G (2008) Lysosomal membrane permeabilization in cell death. Oncogene 27:6434-6451.

Boya P, Andreau K, Poncet D, Zamzami N, Perfettini JL, Metivier D, Ojcius DM, Jäättelä M, Kroemer G (2003) Lysosomal membrane permeabilization induces cell death in a mitochondrion-dependent fashion. J Exp Med 197:1323-1334.

Castino R, Lazzeri G, Lenzi P, Bellio N, Follo C, Ferrucci M, Fornai F, Isidoro C (2008) Suppression of autophagy precipitates neuronal cell death following low doses of methamphetamine. J Neurochem 106:1426-1439.

Chen Y, McMillan-Ward E, Kong J, Israels SJ, Gibson SB (2007) Mitochondrial electron-transport-chain inhibitors of complexes I and II induce autophagic cell death mediated by reactive oxygen species. J Cell Sci 120:4155-4166.

Chu CT, Zhu J, Dagda R (2007) Beclin 1-independent pathway of damageinduced mitophagy and autophagic stress: implications for neurodegeneration and cell death. Autophagy 3:663-666.

Chu Y, Dodiya H, Aebischer P, Olanow CW, Kordower JH (2009) Alterations in lysosomal and proteasomal markers in Parkinson's disease: relationship to alpha-synuclein inclusions. Neurobiol Dis 35:385-398.

Cuervo AM, Stefanis L, Fredenburg R, Lansbury PT, Sulzer D (2004) Impaired degradation of mutant alpha-synuclein by chaperone-mediated autophagy. Science 305:1292-1295.

Dagda RK, Zhu J, Kulich SM, Chu CT (2008) Mitochondrially localized ERK2 regulates mitophagy and autophagic cell stress: implications for Parkinson's disease. Autophagy 4:770-782.

Dauer W, Przedborski S (2003) Parkinson's disease: mechanisms and models. Neuron 39:889-909.

Dauer W, Kholodilov N, Vila M, Trillat AC, Goodchild R, Larsen KE, Staal R, Tieu K, Schmitz Y, Yuan CA, Rocha M, Jackson-Lewis V, Hersch S, Sulzer D, Przedborski S, Burke R, Hen R (2002) Resistance of alpha-synuclein null mice to the parkinsonian neurotoxin MPTP. Proc Natl Acad Sci U S A 99:14524-14529.

Demarchi F, Bertoli C, Copetti T, Tanida I, Brancolini C, Eskelinen EL, Schneider C (2006) Calpain is required for macroautophagy in mammalian cells. J Cell Biol 175:595-605.

Dudley AJ, Bleasby K, Brown CD (2000) The organic cation transporter OCT2 mediates the uptake of beta-adrenoceptor antagonists across the apical membrane of renal LLC-PK(1) cell monolayers. Br J Pharmacol 131:71-79.

Forno LS, Norville RL (1976) Ultrastructure of Lewy bodies in the stellate ganglion. Acta Neuropathol 34:183-197.

Foster KG, Fingar DC (2010) Mammalian target of rapamycin (mTOR): conducting the cellular signaling symphony. J Biol Chem 285:14071-14077.

Goker-Alpan O, Giasson BI, Eblan MJ, Nguyen J, Hurtig HI, Lee VM, Trojanowski JQ, Sidransky E (2006) Glucocerebrosidase mutations are an important risk factor for Lewy body disorders. Neurology 67:908-910.

Hara T, Nakamura K, Matsui M, Yamamoto A, Nakahara Y, SuzukiMigishima R, Yokoyama M, Mishima K, Saito I, Okano H, Mizushima N (2006) Suppression of basal autophagy in neural cells causes neurodegenerative disease in mice. Nature 441:885-889.

Hattingen E, Magerkurth J, Pilatus U, Mozer A, Seifried C, Steinmetz H, Zanella F, Hilker R (2009) Phosphorus and proton magnetic resonance spectroscopy demonstrates mitochondrial dysfunction in early and advanced Parkinson's disease. Brain 132:3285-3297.

Helip-Wooley A, Thoene JG (2004) Sucrose-induced vacuolation results in increased expression of cholesterol biosynthesis and lysosomal genes. Exp Cell Res 292:89-100.

Karageorgos LE, Isaac EL, Brooks DA, Ravenscroft EM, Davey R, Hopwood JJ, Meikle PJ (1997) Lysosomal biogenesis in lysosomal storage disorders. Exp Cell Res 234:85-97.

Kim PK, Hailey DW, Mullen RT, Lippincott-Schwartz J (2008) Ubiquitin signals autophagic degradation of cytosolic proteins and peroxisomes. Proc Natl Acad Sci U S A 105:20567-20574.

Kimura S, Noda T, Yoshimori T (2007) Dissection of the autophagosome maturation process by a novel reporter protein, tandem fluorescenttagged LC3. Autophagy 3:452-460.

Komatsu M, Waguri S, Chiba T, Murata S, Iwata J, Tanida I, Ueno T, Koike M, Uchiyama Y, Kominami E, Tanaka K (2006) Loss of autophagy in the 
central nervous system causes neurodegeneration in mice. Nature 441: $880-884$.

Levine B, Kroemer G (2008) Autophagy in the pathogenesis of disease. Cell 132:27-42.

Luzio JP, Pryor PR, Bright NA (2007) Lysosomes: fusion and function. Nat Rev Mol Cell Biol 8:622-632.

Malagelada C, Jin ZH, Jackson-Lewis V, Przedborski S, Greene LA (2010) Rapamycin protects against neuron death in in vitro and in vivo models of Parkinson's disease. J Neurosci 30:1166-1175.

Mandir AS, Przedborski S, Jackson-Lewis V, Wang ZQ, Simbulan-Rosenthal CM, Smulson ME, Hoffman BE, Guastella DB, Dawson VL, Dawson TM (1999) Poly (ADP-ribose) polymerase activation mediates MPTPinduced parkinsonism. Proc Natl Acad Sci U S A 96:5774-5779.

Martinez-Vicente M, Talloczy Z, Kaushik S, Massey AC, Mazzulli J, Mosharov EV, Hodara R, Fredenburg R, Wu DC, Follenzi A, Dauer W, Przedborski S, Ischiropoulos H, Lansbury PT, Sulzer D, Cuervo AM (2008) Dopaminemodified alpha-synuclein blocks chaperone-mediated autophagy. J Clin Invest 118:777-788.

Mizushima N (2007) Autophagy: process and function. Genes Dev 21: 2861-2873.

Mizushima N, Yoshimori T (2007) How to interpret LC3 immunoblotting. Autophagy 3:542-545.

Narendra D, Tanaka A, Suen DF, Youle RJ (2008) Parkin is recruited selectively to impaired mitochondria and promotes their autophagy. J Cell Biol 183:795-803.

Perier C, Tieu K, Guégan C, Caspersen C, Jackson-Lewis V, Carelli V, Martinuzzi A, Hirano M, Przedborski S, Vila M (2005) Complex I deficiency primes Bax-dependent neuronal apoptosis through mitochondrial oxidative damage. Proc Natl Acad Sci U S A 102:19126-19131.

Perier C, Bové J, Wu DC, Dehay B, Choi DK, Jackson-Lewis V, RathkeHartlieb S, Bouillet P, Strasser A, Schulz JB, Przedborski S, Vila M (2007) Two molecular pathways initiate mitochondria-dependent dopaminergic neurodegeneration in experimental Parkinson's disease. Proc Natl Acad Sci U S A 104:8161-8166.

Ramirez A, Heimbach A, Gründemann J, Stiller B, Hampshire D, Cid LP, Goebel I, Mubaidin AF, Wriekat AL, Roeper J, Al-Din A, Hillmer AM, Karsak M, Liss B, Woods CG, Behrens MI, Kubisch C (2006) Hereditary parkinsonism with dementia is caused by mutations in ATP13A2, encoding a lysosomal type 5 P-type ATPase. Nat Genet 38:1184-1191.

Ravikumar B, Vacher C, Berger Z, Davies JE, Luo S, Oroz LG, Scaravilli F, Easton DF, Duden R, O'Kane CJ, Rubinsztein DC (2004) Inhibition of mTOR induces autophagy and reduces toxicity of polyglutamine expansions in fly and mouse models of Huntington disease. Nat Genet 36:585-595.

Sardiello M, Palmieri M, di Ronza A, Medina DL, Valenza M, Gennarino VA, Di Malta C, Donaudy F, Embrione V, Polishchuk RS, Banfi S, Parenti G,
Cattaneo E, Ballabio A (2009) A gene network regulating lysosomal biogenesis and function. Science 325:473-477.

Sarkar S, Davies JE, Huang Z, Tunnacliffe A, Rubinsztein DC (2007) Trehalose, a novel mTOR-independent autophagy enhancer, accelerates the clearance of mutant huntingtin and alpha-synuclein. J Biol Chem 282: 5641-5652.

Sarkar S, Ravikumar B, Floto RA, Rubinsztein DC (2009) Rapamycin and mTOR-independent autophagy inducers ameliorate toxicity of polyglutamine-expanded huntingtin and related proteinopathies. Cell Death Differ 16:46-56.

Scherz-Shouval R, Elazar Z (2007) ROS, mitochondria and the regulation of autophagy. Trends Cell Biol 17:422-427.

Shults CW (2006) Lewy bodies. Proc Natl Acad Sci U S A 103:1661-1668.

Sulzer D, Mosharov E, Talloczy Z, Zucca FA, Simon JD, Zecca L (2008) Neuronal pigmented autophagic vacuoles: lipofuscin, neuromelanin, and ceroid as macroautophagic responses during aging and disease. J Neurochem 106:24-36.

Tain LS, Mortiboys H, Tao RN, Ziviani E, Bandmann O, Whitworth AJ (2009) Rapamycin activation of 4E-BP prevents parkinsonian dopaminergic neuron loss. Nat Neurosci 12:1129-1135.

Tribl F, Marcus K, Meyer HE, Bringmann G, Gerlach M, Riederer P (2006) Subcellular proteomics reveals neuromelanin granules to be a lysosomerelated organelle. J Neural Transm 113:741-749.

Vila M, Przedborski S (2003) Neurological diseases: Targeting programmed cell death in neurodegenerative diseases. Nat Rev Neurosci 4:365-375.

Vila M, Jackson-Lewis V, Vukosavic S, Djaldetti R, Liberatore G, Offen D, Korsmeyer SJ, Przedborski S (2001) Bax ablation prevents dopaminergic neurodegeneration in the 1-methyl-4-phenyl-1,2,3,6-tetrahydropyridine mouse model of Parkinson's disease. Proc Natl Acad Sci U S A 98:2837-2842.

Vila M, Ramonet D, Perier C (2008) Mitochondrial alterations in Parkinson's disease: new clues. J Neurochem 107:317-328.

Vives-Bauza C, Zhou C, Huang Y, Cui M, de Vries RL, Kim J, May J, Tocilescu MA, Liu W, Ko HS, Magrané J, Moore DJ, Dawson VL, Grailhe R, Dawson TM, Li C, Tieu K, Przedborski S (2010) PINK1-dependent recruitment of Parkin to mitochondria in mitophagy. Proc Natl Acad Sci U S A 107:378-383.

Vogiatzi T, Xilouri M, Vekrellis K, Stefanis L (2008) Wild type alphasynuclein is degraded by chaperone-mediated autophagy and macroautophagy in neuronal cells. J Biol Chem 283:23542-23556.

Yu WH, Dorado B, Figueroa HY, Wang L, Planel E, Cookson MR, Clark LN, Duff KE (2009) Metabolic activity determines efficacy of macroautophagic clearance of pathological oligomeric alpha-synuclein. Am J Pathol 175:736-747.

Zhu JH, Horbinski C, Guo F, Watkins S, Uchiyama Y, Chu CT (2007) Regulation of autophagy by extracellular signal-regulated protein kinases during 1-methyl-4-phenylpyridinium-induced cell death. Am J Pathol 170:75-86. 